\title{
Uma avaliação da Lei de Informática e seus impactos sobre os gastos empresariais em P\&D nos anos 2000
}

Paulo Cesar Brigante*

RESUMO

O presente artigo tem como objetivo avaliar se a Lei de Informática tem sido capaz de provocar aumentos significativos de gastos em P\&D, dando origem aos chamados efeitos de adicionalidade (crowd in). A análise é feita a partir da base de microdados da Pesquisa de Inovação (Pintec-IBGE), pela qual foram construídos três painéis, sendo que cada um abrange dois períodos consecutivos. Com isso, as estimativas possibilitaram verificar os efeitos da lei para os períodos de 2003-2005, 2005-2008 e 2008-2011. Buscando contornar os problemas de viés de seleção, típicos em estimativas de avaliação de políticas de inovação, aplicou-se a metodologia de diferenças-em-diferenças (DID) com covariadas. Embora os resultados indicam não haver efeitos de crowding out, os efeitos de crowd in ocorreram em apenas um período, não sendo possível concluir pela eficácia da lei ao longo de todo o período estudado.

PalaVras-CHAVE | Lei de Informática; Políticas Industriais; Crowd in; Crowding out

Código-JEL | L52

* Faculdade de Ciências e Letras/Universidade Estadual Paulista (FCLAr/UNESP), Araraquara (SP), Brasil. Email: paulo.brigante@ gmail.com. 


\section{An evaluation of the Brazilian Informatics Law} and its impacts on business R\&D expenditure in the 2000's

\section{ABSTRACT}

The purpose of this article is to evaluate if the brazilian informatics law has been able to promote significant private expenditures in $\mathrm{R} \& \mathrm{D}$ resulting in so-called additionality effects (crowd in). The analysis is based on the microdata of the Innovation Research (Pintec-IBGE), through which three panels were constructed, each of which covering two consecutive periods. Through the estimates, it was possible to verify the effects of the law for the periods 2003-2005; 2005-2008 and 2008-2011. In order to overcome the problems of selection bias, which are typical of innovation policy evaluations estimates, it was apllied the differences-in-differences (DID) methodology with covariates. Although the results indicate no crowding out effects, additionality effects occurred in only one period. So, it was not possible to conclude that the law was effective throughout the whole period.

KeYwords | Brazilian Informatics Law; Industrial Policies; Crowd in; Crowding out

JEL CODE | L52 


\section{Introdução}

A Lei de Informática é um instrumento de política industrial de caráter fiscal criado nos anos 1990 com fins de estimular o complexo eletrônico do país por meio de maiores investimentos em pesquisa e desenvolvimento (P\&D). Sendo a redução do IPI o principal benefício para os bens incentivados, a aplicação da lei exige, como contrapartida por parte das empresas, que estas invistam em P\&D e atendam ao chamado Processo Produtivo Básico (PPB). ${ }^{1}$ Nesse sentido, o apoio às atividades de $\mathrm{P} \& \mathrm{D}$ associou-se à internalização de etapas produtivas conforme o PPB.

Uma versão antiga desta lei tem suas origens ainda nos anos 1980, em que os componentes eletrônicos, bem como atividades associadas, contavam com forte apoio protecionista no âmbito da chamada reserva de mercado. Com a definição de novas regras para o setor somente na década de 1990, a primeira edição da Lei de Informática (Lei n. 8.248/91) $)^{2}$ ocorreu no contexto daquela reserva e junto à maior abertura comercial que atravessava o país.

Sob tal aspecto, entre as revisões já feitas na Lei de Informática, destacam-se a de 2001 (Lei n. 10.176/01) e a de 2004 (Lei n. 11.077/04), ambas promovendo alterações na base de cálculo sobre a qual se aplicaria a redução tributária. Por se tratar de um incentivo fiscal que procura estimular os gastos empresariais em P\&D, o presente artigo tem como objetivo avaliar seus impactos sobre tais gastos nas empresas beneficiárias do complexo eletrônico.

Procura-se, com isso, identificar a influência da lei sobre a variação na intensidade de gastos em P\&D em três períodos consecutivos distintos: de 2003 a 2005; de 2005 a 2008 e de 2008 a 2011, por meio da aplicação do método de diferenças-em-diferenças (DID) com inclusão de covariadas.

Grande parte da literatura sobre avaliação de políticas de incentivo à inovação, na qual se enquadra o presente estudo, justifica o uso de instrumentos de apoio à P\&D em razão da existência de falhas de mercado. Em consequência, na ausência de intervenções de políticas, o resultado esperado seriam insuficientes níveis de investimentos em P\&D.

No âmbito das investigações empíricas, esforços econométricos vêm se deparando com a problemática da mensuração dos efeitos das políticas de suporte. E a questão central que domina o debate é se os instrumentos acionados por elas, tanto

1 O Processo Produtivo Básico define-se como um conjunto mínimo de operaçōes que devem ser realizadas no interior da empresa como uma forma de estimular a produção industrial interna.

2 Foi renovada em 2001, Lei n. 10.176/01. 
na modalidade financeira quanto na fiscal, complementam ou, apenas, substituem os gastos privados em $\mathrm{P} \& \mathrm{D}$.

As duas modalidades distinguem-se pela forma em que são usufruídas pelas empresas. No caso dos instrumentos financeiros, como crédito subsidiado e subvenções, os recursos públicos são aportados diretamente nas empresas. Já os incentivos fiscais correspondem a uma alocação indireta de recursos públicos ao permitirem que as empresas reduzam suas obrigações tributárias, desde que cumpram as regras definidas nos determinados programas públicos de P\&D. No caso da Lei de Informática, por ser um incentivo fiscal, cabe perguntar se ela tem sido capaz de estimular os gastos em P\&D das empresas beneficiadas.

Em geral, o desenho dos incentivos fiscais varia entre os países. Os esquemas mais comuns consistem na dedução de gastos correntes em $\mathrm{P} \& \mathrm{D}$ do imposto de renda das empresas, nos créditos tributários e na depreciação acelerada de investimentos em equipamentos e instalações físicas destinadas à $\mathrm{P} \& \mathrm{D}$.

A ocorrência de aumentos nos níveis dos gastos privados em P\&D induzidos pelo uso dos recursos públicos resulta nos chamados efeitos de crowd in, ou adicionalidade, e revela uma situação de complementariedade entre os dois gastos. No caso dos instrumentos financeiros, a complementariedade ocorre pela redução do custo de capital das empresas, via aporte direto de recursos públicos. Ao elevar a taxa de retorno esperada dos investimentos em P\&D, aquela redução deveria atingir um nível suficientemente atrativo, tornando possível o incentivo à elevação dos montantes próprios direcionados à P\&D pelas empresas (DAVID et. al., 2000).

Diferentemente, no caso dos incentivos fiscais a redução se dá no custo de realização da $\mathrm{P} \& \mathrm{D}$, da qual a empresa só fará jus após a efetivação dos gastos. A redução de custos de P\&D, propiciada pelos incentivos, deve ser de magnitude suficiente para provocar maior sensibilidade das empresas a elevarem seus gastos próprios.

Quando os recursos públicos acabam somente substituindo os gastos privados ocorre um efeito contrário, chamado efeito-substituição ou crowding out. Neste caso, o montante realizado de gastos privados, de uma forma ou de outra, ocorreria mesmo na ausência da utilização dos instrumentos públicos pelas empresas beneficiárias.

Ao situarem a Lei de Informática no debate sobre a eficácia das políticas de apoio público à $\mathrm{P} \& \mathrm{D}$, alguns estudos apontam problemas que variam desde o seu desenho, abrangência de empresas, fases do processo em que são concedidos os incentivos, até conflitos de interesses entre grupos de pressão. Para essas abordagens, tais fatores seriam sugestivos de ineficácia da Lei enquanto estimuladora das atividades de P\&D. 
Considerando ser um instrumento aplicado a um setor sujeito a elevados riscos tecnológicos e de mercado, justifica-se avaliar os impactos da Lei de Informática, buscando entender em que medida ela tem sido eficaz em promover respostas positivas dos investimentos em P\&D no Brasil. A maioria desses estudos possui ênfase qualitativa, muitas vezes baseadas em amostras de poucas empresas, mas converge ao concluir pela baixa capacidade de estimular aumentos.

Por outro lado, análises quantitativas voltadas à mensuração dos seus efeitos apenas sobre os gastos em $\mathrm{P} \& \mathrm{D}$ são escassas e não abrangem o período mais recente proposto neste artigo. Observa-se, assim, que possíveis lacunas podem ser preenchidas tanto pela aplicação de métodos de estimação ainda não testados, quanto pelo exame dos impactos da Lei em períodos distintos aos já cobertos pela literatura.

Sob o primeiro aspecto, o artigo contribui adotando o método DID com covariadas. Este método é versátil em captar efeitos de políticas e, ao mesmo tempo, diferencia-se de abordagens mais usuais por permitir o acompanhamento das mesmas empresas em dois momentos distintos: antes e depois do uso da Lei.

Quanto ao segundo aspecto, o acesso às bases de microdados de 2009-2011, junto às bases anteriores de 2003-2005 e 2006-2008, possibilitou estender a análise para o período mais recente, ainda não coberto pelas análises anteriores.

A avaliação empírica dos efeitos da Lei de Informática torna-se importante para as formulações e desenho das políticas industriais e de inovação no país, precisamente, enfocando grande parte dos anos 2000. Naquele momento houve um retorno das políticas industriais e de inovação no país, objetivando elevação nos gastos empresariais em P\&D. Esperavam-se, então, aumentos da relação entre os mesmos e o produto interno bruto (P\&D/PIB), reduzindo a distância em termos de esforços tecnológicos do Brasil em relação a outros países.

Os dados da Pesquisa de Inovação (Pintec), nas quatro bases utilizadas neste estudo, mostram um crescimento no número de empresas beneficiárias da Lei. Resta saber em que medida este aumento associou-se a gastos mais intensivos em P\&D por parte das mesmas.

Diferentemente da maioria dos estudos com base em microdados de empresas inovadoras que, em geral, realizam estimativas para apenas um período, foi possível acompanhar as mesmas empresas em dois períodos. A partir de comparações entre beneficiárias e não-beneficiárias, o acompanhamento permitiu estimativas de variação de gastos, e não dos níveis, de um período para outro.

A seguir, é feita uma revisão da bibliografia sobre políticas de avaliação tratando dos aspectos teóricos e empíricos encontrados na literatura internacional. Neste 
último aspecto, destacam-se os métodos utilizados para lidar com o problema do viés de seleção em estimativas de impactos de políticas e obter os efeitos de crowd in e crowd out. Algumas especificidades sobre a Lei de Informática, bem como sua evolução, características e aspectos da literatura no Brasil, também serão abordadas. Posteriormente, apresentam-se os dados utilizados e o método de diferenças-em-diferenças com covariadas (DID) aplicado sobre as bases da Pintec (2003, 2005, 2008 e 2011). Por fim, discutem-se os resultados do modelo.

\section{Revisão da literatura}

As origens teóricas sobre a necessidade de intervenções políticas de apoio à $\mathrm{P} \& \mathrm{D}$ encontram-se nos argumentos clássicos de Arrow (1962) e Nelson (1959), em que o problema dos baixos níveis de investimentos em $\mathrm{P} \& \mathrm{D}$ associa-se às falhas de mercado.

Inicialmente, a razão apontada devia-se à impossibilidade de apropriação plena dos retornos daquelas atividades, dado que o conhecimento é considerado um bem não rival (non-rival good) e não excludente (non-excludable) no sentido clássico de bem comum.

A ideia central era que o conhecimento que origina a inovação não poderia ser mantido indefinidamente tácito. De igual maneira, também não poderia ser plenamente apropriado pela firma inovadora. Assim, a taxa de retorno privado ficaria abaixo da taxa de retorno social e este seria um dos motivos que justificava a intervenção de políticas de suporte à $\mathrm{P} \& \mathrm{D}$.

Posteriormente, um segundo tipo de falha ainda persistiria, conforme lembram Hall e Lerner (2010), derivado das imperfeiçóes no mercado de capitais, como assimetrias de informaçôes e risco moral, provocando, consequentemente, um "gap" entre a taxa de retorno privado e o custo de capital. A razão decorria do fato de o investidor em inovação e o financiador serem entidades diferentes, sujeitas àquelas imperfeições.

O referencial teórico acima, ao apontar os problemas inerentes aos investimentos em P\&D, iluminou uma literatura voltada para avaliação das políticas industriais e de inovação. A ênfase dessa literatura tem sido o uso de instrumentos de apoio publico à $\mathrm{P} \& D$ em razão daquelas falhas que resultariam em níveis de investimentos abaixo do ótimo (underinvestment). Nessa abordagem enquadram-se os trabalhos de Klette et al. (2000) e Hall e Van Reenen (1999).

Embora sob diferentes perspectivas, mas procurando a existência dos mesmos vínculos, os autores indagaram se o crédito subsidiado, ou os incentivos fiscais, 
deveriam gerar um efeito indutor sobre aqueles investimentos preenchendo o gap e possibilitando o retorno ao seu nível ótimo. Dessa forma, nas análises de avaliação a ênfase empírica, procura-se mensurar o impacto dos instrumentos de apoio sobre os estímulos privados à $\mathrm{P} \& \mathrm{D}$ empresarial. Em sua maioria, a $\mathrm{P} \& \mathrm{D}$ empresarial é representada pelos gastos realizados naquelas atividades ou pela intensidade de $\mathrm{P} \& \mathrm{D}$ (gastos em $\mathrm{P} \& \mathrm{D}$ em relação à receita líquida), comumente tratada como esforços de inovação (inputs) (ASCHHOFF, 2009 CZARNITZKI; HUSSINGER, 2004). ${ }^{3}$

Assim, para avaliar em que medida os instrumentos de suporte público presentes nas políticas estimulam novas atividades de P\&D, ou níveis mais elevados de gastos privados, adota-se como critério o conceito de adicionalidade (input additionality). Os casos de elevações positivas e significativas de gastos privados são conhecidos também como efeitos de crowd in, de onde se infere o papel positivo dos instrumentos já que, na ausência deles, o acréscimo de gastos não seria observado (BUISSERET; CAMERON, 1995).

Por outro lado, casos opostos em que os gastos privados são apenas substituídos pelos gastos públicos dão origem aos chamados efeitos de substituição, ou crowding out.

Considera-se, então, a hipótese de que as empresas apoiadas têm incentivos para reduzir o custo da P\&D e substituírem seus gastos próprios pelos fundos públicos. Isso implica saber o quanto tal empresa teria gasto caso não tivesse recebido o apoio.

Assim, uma das questões presentes quanto à eficácia das políticas de inovação é saber se os instrumentos acionados por elas, tanto na modalidade financeira quanto na fiscal, complementam, ou apenas substituem, os gastos privados em P\&D. No caso da Lei de Informática, cabe perguntar se ela tem sido capaz de estimular os gastos em P\&D das empresas beneficiadas.

Vale mencionar que a ocorrência de crowding out caracteriza um risco que ameaça o sucesso e a eficácia das políticas. Essa é a razão que justifica a importância da avaliação dos seus resultados. Nesse sentido, a literatura empírica tem sido extensa, porém sujeita a divergências e falta de consenso conforme análise de David et al. (2000), em que se encontra um conjunto de estudos dessa natureza. A diversidade na fonte de dados, além das diferenças metodológicas quanto às unidades de análise, níveis de agregação que variam desde empresas, setores da

3 Muito embora haja tal predomínio, existem também outras análises que se propõem a avaliar os resultados da inovação (outputs) por meio de variáveis de desempenho, tais como patentes obtidas pela firma, exportações, vendas, etc. 
indústria, laboratórios e até países, estaria entre as causas. A isso somam-se os critérios de decisão de escolhas dos projetos feitos pelas agências oficiais (GARCÍA-QUEVEDO et al., 2008).

David e Hall (2000), reforçando o argumento da análise citada acima, chamam a atenção para a falta de um modelo estrutural que fundamentasse as análises empíricas, argumentando ser necessário um modelo formal no qual seria possível identificar os canais pelos quais os gastos públicos em P\&D impactam os gastos empresariais privados. ${ }^{4}$

Até os anos 1990 a maior parte dos estudos empíricos restringia-se às firmas dos EUA e, com algumas exceções, Canadá. Leyden Link (1990), com base em uma amostra de dados de laboratórios de 120 empresas norte-americanas, encontraram evidências de que o suporte governamental à $P \& D$ contribuía para elevar não somente o nível dos gastos privados em $\mathrm{P} \& \mathrm{D}$, mas também o de outras atividades inovativas. Howe e Mcfetridge (1976) examinaram empresas canadenses mais intensivas em tecnologia nos setores elétrico, químico e máquinas e equipamentos, não encontrando efeitos positivos e significativos dos subsídios para todos eles.

As aplicações empíricas em vários países tornaram-se mais extensas a partir dos anos 2000. Wallsten (2000), ao analisar os dados para pequenas empresas do programa SBIR (Small Business Innovation Research), encontrou evidências de crowding out. Em seu estudo, o autor chamava a atenção para a necessidade de lidar com o problema da endogeneidade em programas públicos. Busom (1999), em uma amostra de 147 empresas espanholas, embora tenha verificado evidências de aumento de esforços inovativos, concluiu que os efeitos de crowding out não poderiam ser descartados para 30\% delas.

Lach (2002) examinou um painel de empresas israelenses com dados entre 1990 e 1995 aplicando estimativas em diferenças-em-diferenças (DID). Embora tenha observado efeitos positivos dos subsídios à $\mathrm{P} \& \mathrm{D}$ sobre os gastos privados, os mesmos não foram significativos. Além disso, o autor estendeu sua análise com estimativas em painel dinâmico, buscando captar efeitos a longo prazo dos subsídios sobre os gastos em P\&D. A conclusão foi que, embora positivos, os efeitos ficavam abaixo dos resultados esperados pelas políticas (dollar by dollar).

Nas análises voltadas somente para avaliação dos incentivos fiscais aplicadas em vários países, também é possível encontrar resultados diversos. Em estudo recente

4 Entre os canais destacavam-se tanto as características das empresas quanto as setoriais. Alguns deles seriam: competências tecnológicas das firmas; condições de demanda; oportunidades tecnológicas; apropriabilidade; etc. 
com dados da Noruega, Itália e França, Bodas Freitas et al. (2017) encontraram efeitos de adicionalidade para as empresas localizadas em setores em que a P\&D constitui estratégia predominante de inovação das empresas, sobretudo naqueles baseados em ciência, seguindo a taxonomia de Pavitt (1984).

Marino et al. (2016) utilizaram dados para uma amostra de empresas francesas entre 1993 e 2009, combinando os métodos de DID com propensity score. Diferenciando-se da maioria das abordagens anteriores, este estudo simulou testes com diferentes dosagens de tratamento a fim de encontrar se há uma quantidade ótima de incentivos que leva à adicionalidade. Não houve efeitos significativos nem de adicionalidade e nem de substituição, sendo que, para níveis considerados médios de dosagens, os incentivos fiscais parecem gerar efeitos de crowding out.

Em uma extensa revisão de estudos aplicados à OCDE, Hall e Van Reenen (2000) utilizaram vários métodos e fontes de dados e apresentaram diferentes arranjos em que se organizam os incentivos fiscais. Os autores concluem que os incentivos fiscais são capazes de estimular gastos adicionais de P\&D ao afetarem as decisões de investimento em P\&D.

Entre os estudos destacados pelos autores encontra-se o de Bloom, Griffith e Reenen (2002), que examinaram um painel de vários países da OCDE e tiveram como conclusão principal que, no curto prazo, uma redução nos custos da P\&D de, aproximadamente, $10 \%$ induz a elevação de níveis de gastos privados próximos a $1 \%$. Já no longo prazo, para o mesmo nível de redução, o aumento médio era de $10 \%$ nos gastos, não havendo, assim, substituição de gastos.

Algumas características que diferenciam os incentivos fiscais de outras modalidades, como o crédito subsidiado, por exemplo, e que têm possíveis implicações nos resultados esperados dos gastos em P\&D, segundo a literatura, são mencionadas no item a seguir que trata da Lei de Informática.

\subsection{Lei de Informática: evolução, principais características e limitações}

A Lei de Informática trata-se de um instrumento de política industrial de caráter fiscal criado nos anos 1990, com fins de estimular o complexo eletrônico do país. Uma versão antiga desta Lei tem suas origens ainda na década de 1980, em que os componentes eletrônicos, bem como atividades a ele ligadas, contavam com forte apoio protecionista no âmbito da chamada reserva de mercado. Com a definição de novas regras para o setor somente nos anos 1990, a primeira edição da Lei de 
informática (Lei n. 8.248/91) se deu no contexto daquela reserva para o setor de informática e junto à maior abertura comercial que atravessava o país.

Com a regulamentação em 1993, procurava-se estimular a competitividade das empresas, via redução do Imposto sobre Produtos Industrializados (IPI), e conciliar o regime de incentivos da Zona Franca de Manaus (ZFM) ao regime praticado nas demais regiōes do país. Tratou-se, portanto, de um mecanismo de incentivo fiscal cuja exigência sobre as empresas beneficiárias era o investimento mínimo de 5\% do faturamento em $\mathrm{P} \& \mathrm{D}$, os quais poderiam distribuir-se em até 3\% nas atividades internas e os $2 \%$ restantes em atividades cooperativas com universidades, institutos de pesquisas ou em programas públicos. Por outro lado, ao ser um instrumento com fins de conciliar regimes tributários diferenciados entre a ZFM e outras regiōes, a Lei possibilitou que as empresas destas últimas pudessem ser beneficiadas pelos incentivos fiscais, via isenção de IPI, de 15\% para a maioria dos produtos.

A Lei passou por revisóes até 2001 (Lei n. 10176/01) e sua aplicação exige contrapartida por parte das empresas. A redução do IPI, enquanto principal incentivo para os bens incentivados, ocorre desde que as empresas invistam em P\&D e atendam ao chamado Processo Produtivo Básico (PPB), ${ }^{6}$ sendo esta última uma exigencia com objetivos de garantir que algumas etapas do processo de produção fossem internalizadas no país.

Embora tal regra (Lei n. 8.248/91) possa ter gerado aumentos significativos nos valores investidos em $\mathrm{P} \& \mathrm{D}$ pelas empresas, um fato apontado pela literatura é a difículdade em mensurar o montante de recursos efetivamente destinados à P\&D, uma vez que as empresas buscam, por vezes, enquadrar diversas outras atividades nesta conta $^{7}$ (GARCIA; ROSELINO, 2004, p. 179)

Apesar de a estrutura de incentivos no país contar com outras modalidades, como a Lei n. 11.196/05 (Lei do Bem), ainda é notável a concentração dos incentivos fiscais à $\mathrm{P} \& \mathrm{D}$ no Lei de Informática, conforme exibem os relatórios do Ministério da Ciência, Tecnologia e Inovação (MCTI). ${ }^{8}$

No que diz respeito aos estudos sobre a Lei de Informática, nota-se que a mesma tem sido abordada em diversos trabalhos de ênfase qualitativa. Levantam-se, em tais casos, alguns aspectos que, supostamente, comprometem sua eficácia enquanto

5 Foi renovada em 2001, Lei n. 10176/1.

6 O Processo Produtivo Básico define-se como um conjunto mínimo de operaçōes que devem ser realizadas no interior da empresa como uma forma de estimular a produção industrial interna.

7 Durante o período, algumas empresas criaram instituiçōes de pesquisa com identidade jurídica independente na forma de "fundaçôes", para direcionar os investimentos exigidos em instituiçôes de pesquisa (GARCIA; ROSELINO, 2004).

8 Disponível em: <http://www.mct.gov.br/index.php/content/view/9252.html>. 
instrumento de estímulos aos investimentos em $\mathrm{P} \& \mathrm{D}$. Um exemplo refere-se à exigência do cumprimento dos Processos Produtivos Básicos (PPB).

Algumas abordagens sobre o complexo eletrônico concluíram que a baixa densidade das etapas produtivas internas seria um dos principais problemas envolvidos nas cadeias de produção do setor. E, como resultado, a P\&D realizada internamente voltar-se-ia para atividades de menor complexidade, em que o retorno esperado é mais baixo, restringindo, portanto, os montantes investidos.

Este problema foi apontado por Maria e Gutierrez (2010) ao tratarem da produção de componentes locais, cujo objetivo era contribuir para um maior adensamento de toda a cadeia produtiva. Entretanto, acabou abrindo espaço para as demais indústrias do complexo realizarem processos de montagens para o mercado interno. Consequentemente, os gastos em $\mathrm{P} \& \mathrm{D}$ resultantes não necessariamente vinculam-se a fortes aumentos de valor agregado e ganhos de competitividade externa, já que os processos de montagem correspondem a uma etapa da produção que agrega menos valor. Os autores observaram que, apesar de haver a montagem completa do produto, a produção de componentes é insuficiente e rara no Brasil, restringido, assim, o próprio desenvolvimento da $\mathrm{P} \& \mathrm{D}$ local.

Garcia e Roselino (2004) ressaltaram problemas semelhantes. Para os autores, a Lei seria ineficaz, entre outros motivos, por não resultar em internalização de novas capacitações direcionadas ao desenvolvimento de produtos mais complexos por parte das grandes empresas multinacionais. A realização dos PPB, enquanto instrumento para que as empresas cumprissem os requisitos mínimos de produção e usufruirem dos benefícios fiscais, não representou, no caso das montadoras, esforços adicionais expressivos de P\&D. ${ }^{9}$

A nova versão da Lei (Lei n. 10176/01) implicou sua inclusão como instrumento de política de desenvolvimento regional, uma vez que percentuais obrigatórios deveriam ser alocados nas regiōes Nordeste, Amazônica ou Centro-Oeste $(0,8 \%)$ e outra parte deveria ser alocada no FNDCT (Fundo Nacional de Desenvolvimento Científico e Tecnológico), que também estabelecia percentuais obrigatórios para essas regiōes. Além disso, previa-se, como exigência de contrapartida, a aplicação dos mesmos $5 \%$ do faturamento bruto no mercado interno em atividades de P\&D, modificando sua distribuição entre $2,7 \%$ e $2,3 \%$ em atividades externas de P\&D. ${ }^{10}$

9 Os autores argumentam que somente a montagem de placas e dos equipamentos internamente já seria suficiente para cumprir as exigências de internalização da produção, revelando que o instrumento seria ineficaz, sob tal aspecto (GARCIA; ROSELINO, 2004, p. 182).

10 Além dos já citados, outros benefícios adicionais para redução do IRPJ referentes a despesas de P\&D, capitalização das empresas e preferência nas compras públicas. Ver Porto e Kannebley (2012). 
No entanto, estabelecia-se que nestas últimas houvesse percentuais obrigatórios de aplicação nas regiōes Norte, Nordeste e Centro-Oeste do país. ${ }^{11}$

Nesse sentido, ao incluir o desenvolvimento regional também como um objetivo, a Lei é interpretada por alguns não como um instrumentovoltado para P\&D, mas sim como uma norma que busca o equilíbrio regional. ${ }^{12}$ A sua importância decorre muito mais da necessidade de se conciliar a produção de software no Brasil com a existência de três regimes tributários distintos: a produção da Zona Franca, a das outras regiōes e a produção importada. Assim, questiona-se a sua efetividade em incentivar a P\&D e a inovação propriamente dita (PACHECO, 2011).

No início da Lei previa-se redução gradativa da isenção do IPI até 2009. No entanto, com as alteraçôes no âmbito da Lei n. 11.077/04, os prazos de redução estenderam-se até o fim de 2019, ${ }^{13}$ momento em que se programava atingir sua extinção. No mesmo contexto, somou-se a mudança na base de cálculo de incidência dos incentivos.

De 1991 a 2001 deduziam-se os tributos referentes à comercialização dos produtos incentivados do faturamento bruto das empresas no mercado interno e aplicava-se a base de cálculo. Entre 2001 e 2003 passou-se a considerar, também, as aquisiçôes de produtos incentivados. Com as alterações de 2004, a base de cálculo passou a ser o faturamento bruto no mercado interno somente decorrente dos produtos incentivados na forma da Lei. ${ }^{14}$

No trabalho de Salles Filho et al. (2012), com base nos resultados de uma pesquisa em parceria entre o Centro de Gestão e Estudos Estratégicos (CGEE) e o Grupo de Estudo sobre Organização da Pesquisa e da Inovação (Geopi), ${ }^{15}$ afirma-se que a Lei estimulou as atividades de P\&D no país. Porém, a mudança da base de cálculo dos incentivos, em 2002 e 2004, teria levado os investimentos a situarem-se em patamares inferiores ao início dos anos 2000.

A conclusão deste estudo é que, embora a Lei seja capaz de promover o aumento da capacidade de inovação, esta se limita às de baixa densidade científica

\footnotetext{
11 Há uma diferenciação entre as empresas com faturamento bruto inferior a 15 milhôes de reais, as quais podem investir apenas em P\&D interna. A maior parte das empresas beneficiada é de pequeno e médio portes e, por se enquadrarem em faturamentos abaixo de R $\$ 15$ milhōes, a aplicação de P\&D é livre.

12 Este aspecto confere à Lei de Informática um caráter singular, pois, caso não houvesse o incentivo redutor do IPI, a produção migraria para a Zona Franca de Manaus. Ver Pacheco (2011).

13 A Lei n. 11.077/04 alterou as Leis n. 8.248 e 8.387, ambas de 1991, bem como a Lei n. 10176/01, prevendo redução de 80\% do imposto devido até $2014,75 \%$ até 2015 e $70 \%$ de 2016 até 2019, quando, então, ocorreria sua extinção.

14 Art.11. Disponível em: <http://www.planalto.gov.br/ccivil_3/leis/LEIS_2001/L10176.htm>.

15 Do Departamento de Política Científica e Tecnológica da Universidade de Campinas (DPCT-Unicamp).
} 
e tecnológica, concentrando-se mais no desenvolvimento de produtos do que na pesquisa e abertura de novos mercados (SALLES FILHO et al., 2012, p. 23). Além disso, enquanto instrumento de estímulo à competitividade, ressalta-se que grande parte do complexo eletrônico no país apresenta déficits comerciais. Os estimulos aos investimentos em $\mathrm{P} \& \mathrm{D}$ visavam maior agregação interna de valor como forma de reduzi-los. No entanto, a política não teria sido eficaz para evitar a contínua importação de itens de maior valor, como componentes, resultando assim no agravamento do déficit comercial do setor. ${ }^{16}$

Prochnik et al. (2015) abordaram a influência dos grupos de interesses entre fabricantes da ZFM e de outras regiōes. Uma das conclusões é que a Lei resulta destes interesses, sendo que a análise dos projetos, antes de obedecer a critérios claros quanto à eficácia de emprego de recursos, atende à necessidade de equilibrar os interesses da ZFM com empresas de outras regiōes.

O debate em torno da eficácia das políticas é tratado na extensa resenha elaborada por David et al. (2000). Nela, situações em que as escolhas tendem a ser influenciadas por grupos de pressão ou, então, em que a necessidade de demonstrar sucesso de políticas nem sempre leva às escolhas ótimas em termos de projetos são exemplos típicos de "falhas do governo" (government failures). Trata-se de outro tipo de falha ao qual estão sujeitas as políticas, além das conhecidas falhas de mercado.

Um ponto destacado pela literatura é que uma das principais diferenças de um incentivo fiscal em comparação aos créditos subsidiados é a menor discricionariedade quanto à sua aplicação. Além disso, esta aplicação é feita após a empresa ter realizado os gastos e desembolsado os recursos em um determinado projeto. Ao contrário dos financiamentos, que são concedidos antes que as empresas os desembolsem.

$\mathrm{Na}$ maioria dos programas públicos essa modalidade de incentivos não implica, necessariamente, escolhas setoriais por parte das políticas. Por outro lado, ela confere maior autonomia de decisões às empresas quanto aos projetos que serão apoiados. É sob esse aspecto que Montmartin e Herrera (2014) consideram que o apoio a projetos de $\mathrm{P} \& \mathrm{D}$ via incentivos fiscais reflete decisões muito mais inerentes às empresas, e não às escolhas dos formuladores de políticas; ou, então, critérios de decisões alocativas do mercado, em vez de intenções alocativas de políticas governamentais.

16 Um outro aspecto da Lei, que foi previsto para operar como indutor de mais gastos privados em P\&D, é o fato da mesma prever prioridade nas compras públicas, o que representa um potencial efeito de demanda que, supostamente, estimularia os investimentos em tais atividades. A abrangência deste aspecto se dá tanto sobre bens de tecnologia nacional quanto sobre aqueles que seguem a regra do PPB. 
Ao se analisar a Lei enquanto um incentivo fiscal, são necessárias algumas ressalvas em relação a essas diferenças com possíveis implicações nos resultados esperados dos gastos em P\&D.

Prochnik et al. (2015) sublinham que o acesso aos benefícios fiscais da Lei a distingue das características típicas de um incentivo fiscal propriamente dito. Embora haja um desconto sobre um imposto, o IPI, fato que a caracteriza como uma modalidade fiscal propriamente dita, a exigência de seguir o PPB como condição de acesso ao incentivo do IPI requer que as empresas submetam um projeto de produção para ser aprovado. E, nesse caso, trata-se de uma característica mais próxima da modalidade de crédito subsidiado. Mas, por outro lado, uma das diferenças dos incentivos fiscais em relação aos financiamentos é que as empresas usufruem do benefício somente após realizar e desembolsar recursos em um determinado projeto. ${ }^{17}$

Além disso, aponta-se como um fato que compromete a sua eficácia o descasamento existente entre projetos de $\mathrm{P} \& \mathrm{D}$ e processos de produção. Os gastos em $\mathrm{P} \& \mathrm{D}$ são realizados depois da fase em que se desenvolveu o processo de produção, e que o projeto foi apresentado. De tal forma que os investimentos em P\&D referem-se a atividades incentivadas realizadas à posteriori. (Prochnik et al., 2015, p. 145).

Por fim, tendo em vista que a Lei de Informática constitui um incentivo fiscal com exigência de contrapartida em gastos em P\&D, seria lícito esperar das empresas beneficiárias volumes mais elevados de recursos próprios destinados à $\mathrm{P} \& \mathrm{D}$ em relação às não beneficiárias. Por si só, esse aspecto leva a supor uma probabilidade de ocorrência de crowd in mais elevada do que a de crowd out. Tal fato reforça a necessidade de aprofundamento dos estudos empíricos, conforme se comenta no item seguinte.

\subsection{Abordagens empíricas da Lei: objetivos, efeitos e limitações}

Os estudos mencionados anteriormente convergem ao apontar os problemas mencionados como obstáculos que comprometem a eficácia da Lei enquanto estimuladora dos investimentos em P\&D. Ao mesmo tempo, estudos econométricos que procuram estimar seus efeitos sobre empresas beneficiárias são escassos no Brasil, sugerindo a necessidade de avaliações quantitativas que complementem as análises de caráter qualitativo.

Um exemplo destes estudos é o de Kannebley Jr. e Porto (2012), que analisaram os efeitos sobre os investimentos em P\&D utilizando dados de 2001 a 2008. Os $17 \mathrm{O}$ contrário ocorre com os financiamentos que poderão ser concedidos antes da realização. 
autores não encontraram evidências de que as empresas beneficiárias elevassem seus dispêndios em P\&D interna. As estimativas foram realizadas em mínimos quadrados ordinários agrupados (OLS pooled), mínimos quadrados ordinários com efeitos fixos e Tobit com efeitos fixos.

Estudo recente de Avellar e Botelho (2016) analisou o efeito de vários programas públicos de incentivo à inovação, entre eles a Lei de Informática, aplicando estimativas em propensity matching score, porém, restritas às pequenas empresas. Com base nos dados de 2006-2008 (Pintec 2008), as autoras estimaram os efeitos dos incentivos fiscais em conjunto e desagregados pela Lei do Bem e Lei de Informática, não encontrando evidências de que os mesmos estimulem os gastos superiores em relação às pequenas empresas não beneficiadas.

Outras estimativas foram feitas por Ribeiro et al. (2011) analisando os efeitos da Lei sobre a produtividade de empresas beneficiárias do setor de informática (ISIC 3). Os autores aplicaram uma metodologia de avaliação de impactos por meio de um modelo de decomposição do crescimento da produtividade em empresas do setor, entre 1996 e 2005.

No estudo foram utilizados um modelo Logit para descrever as características observáveis das firmas beneficiárias, um modelo com controles de observáveis para avaliar os impactos da Lei e um modelo sem controle. A conclusão foi que a Lei não parece influenciar a produtividade das empresas beneficiárias, seja controlando as características ou não.

Os autores testaram estimativas agrupadas e, também, em efeitos fixos, concluindo que as firmas de baixa produtividade são as mais beneficiadas. Uma das possíveis explicaçôes é a ênfase da Lei sobre produtos finais e direcionados ao mercado interno, assim como de determinadas condicionalidades em relação aos gastos em $\mathrm{P} \& \mathrm{D}$, os quais parecem limitar seus efeitos.

Do ponto de vista empírico, as dificuldades envolvidas para a mensuração dos impactos dos instrumentos têm levado os esforços econométricos ao desenvolvimento de vários modelos que se distinguem por suas especificações, tipos de dados utilizados, variáveis que representam as políticas, etc.(CERULLI; POTİ, 2012).

Um exemplo das dificuldades refere-se às escolhas feitas pelas agências. É consenso na literatura sobre avaliação de políticas que a participação de empresas em programas de apoio público à $\mathrm{P} \& \mathrm{D}$ e inovação caracteriza-se pela falta de aleatoriedade nas escolhas governamentais, dando origem a problemas de endogeneidade (CZARNITZKI; \& LICHTENBERG, 2005; CRESPI et al., 2011). 
Nesse sentido, há elevada probabilidade de que as empresas selecionadas em programas públicos resultem de escolhas com base em suas características ou em preferências dos formuladores. Em razão disso, as estimativas que buscam avaliar o impacto das políticas estarão fortemente sujeitas a um viés de seleção nos resultados.

A literatura tem apontado diversos métodos para lidar com este problema, dos quais se destaca o método de diferenças em diferenças (DID) com covariadas, empregado neste trabalho. Com tal abordagem, é possível amenizar o viés das estimativas causado pelos fatores não observáveis, desde que seja possível aplicar à base de dados uma estrutura de painel de efeitos fixos, conforme será visto adiante. Ao mesmo tempo, a inclusão de variáveis de controle ameniza o viés advindo dos fatores observáveis.

Conforme mencionado anteriormente, a escassez de estudos voltados para mensuração dos efeitos da Lei abre lacunas tanto em termos dos períodos de análise, quanto dos métodos empregados para verificar seus efeitos.

Nesse sentido, para atingir o objetivo proposto pelo artigo de avaliar os impactos da Lei sobre os gastos em P\&D nas empresas, o emprego do método DID com covariadas possibilita uma abordagem distinta dos estudos anteriores. Isso tanto pelo fato de ser um método ainda não testado pela literatura, quanto pela disponibilidade de dados que permitiram a construção de painéis cobrindo três períodos distintos e ao mesmo tempo possibilitando, em cada um, o acompanhamento das mesmas empresas, antes e depois do uso do instrumento. Tais aspectos serão tratados em mais detalhes na seção seguinte.

\section{Dados e método}

Nas estimativas que serão apresentadas os dados foram extraídos das quatro bases de microdados da Pintec (IBGE) referentes aos triênios 2001-2003 (base 1: Pintec 2003), 2003-2005 (base 2: Pintec 2005), 2006-2008 (base 3: Pintec 2008) e 20092011 (base 4: Pintec 2011). Na amostra foram selecionadas apenas as empresas que apresentaram gastos positivos em $\mathrm{P} \& \mathrm{D}$ para cada período com base na Classificação Nacional das Atividades Econômicas, nível de desagregação 3 (CNAE-2) para os setores alta tecnologia, de acordo com o critério da Organização para a Cooperação e Desenvolvimento Econômico (OCDE), ${ }^{18}$ e que pertencem ao complexo eletrônico do país. Dessa forma, os grupos de tratamento e de controle foram construídos

18 Os setores pertencentes são: instrumentação; informática; eletrônico, telecomunicações; e aeronaves. 
a partir de empresas que realizaram P\&D nos setores de informática, eletrônica, comunicações e instrumentação.

Com as quatro bases foram criados três painéis agrupados em períodos consecutivos: um primeiro incorporando os dados tanto das publicações de 2003 e 2005; o segundo com dados de 2005 e 2008; e o terceiro com dados de 2008 e 2011. Para cada painel foram criados grupos de tratamento e de controle definidos da seguinte forma: no primeiro grupo, as empresas beneficiárias da Lei no período ", mas que não foram beneficárias em ; no segundo grupo, as empresas que não se beneficiaram em nenhum dos dois momentos. ${ }^{19}$

Pela estimativa de diferenças em diferenças (DID), o cálculo do estimador envolve dois procedimentos: um primeiro em que se toma a diferença na média entre os gastos de P\&D de cada grupo antes do uso dos benefícios, e esta mesma diferença depois que as empresas submeteram-se ao tratamento; e o segundo, em que se tira a primeira diferença dos resultados ao longo do tempo. ${ }^{20}$ Dessa forma, obtém-se um estimador cujo grau de significância permitirá avaliar se a Lei foi efetiva em produzir aumentos significativos na intensidade de gastos em $\mathrm{P} \& \mathrm{D}$ ou não.

Assim, a aplicação do método DID permite a obtenção de um estimador que mede o efeito de uma intervenção de política sobre as empresas (o grupo de tratamento), comparando-o em relação a um outro grupo que não tenha sofrido os impactos da intervenção (o grupo de controle). Com tal procedimento pretende-se avaliar se houve efeitos de adicionalidade (crowd in) ou de substituição (crowd out) advindos do uso que as empresas fizeram dos benefícios da Lei de Informática.

Tal método é considerado uma ferramenta econométrica simples e bem estabelecida (LECHNER, 2011). O aspecto fundamental é que sua aplicação ocorre em casos em que os dados são provenientes de um experimento natural (ou quase-experimento) e os grupos de tratamento e de controle surgem de mudanças específicas (alterações exógenas) da política governamental e não resultam de escolhas aleatórias (WOOLDRIDGE, 2011). Uma de suas vantagens é a possibilidade de controlar características não observáveis e invariantes no tempo (HECKMAN et al., 1998).

No presente artigo, a possibilidade de acompanhar as mesmas empresas em cada painel de dois anos justificou a escolha do método e representou uma abordagem ainda não empregada na literatura que procurou avaliar os impactos da Lei de Informática. Assim, apesar de comparar unidades heterogêneas, foi possível

19 Exemplo: no painel referente a 2003-2005, o grupo de tratamento é formado pelas empresas que beneficiaram-se da Lei em 2005, mas que não se beneficiaram em 2003, enquanto o grupo de controle é constituído por aquelas que não se beneficiaram em nenhum dos dois momentos.

20 Entre $t$ " e $t-1$, considerando-se que cada estimativa tem três períodos: 2003 e 2005; 2005 e 2008; 2008 e 2011. 
amenizar o problema do viés de seleção, além de permitir a inclusão de covariáveis para controlar o viés de observáveis.

É fato reconhecido na literatura sobre avaliação de políticas que a aplicação (uso) de determinados instrumentos de apoio à PD\&I por parte das empresas não ocorre por meio de escolhas aleatórias por parte das agências governamentais (CZARNITZKI; ALMUS, 2010).

Desde que o tratamento não seja atribuído aleatoriamente, mas sim com base nas características ou preferências dos indivíduos, os resultados que buscam avaliar o impacto das políticas estarão fortemente sujeitos a refletir o efeito tanto do tratamento quanto da atribuição não aleatória, dando origem a um viés de seleção nas estimativas. A ausência de aleatoriedade implica que a aplicação da Lei leve em consideração algumas características específicas a determinadas empresas, as quais influenciam diretamente nos gastos em $\mathrm{P} \& \mathrm{D}$.

Por outro lado, as empresas que exibem níveis mais elevados de gastos em $\mathrm{P} \& \mathrm{D}$ terão maior probabilidade de sucesso em projetos públicos subsidiados, levando as mesmas à autosseleção (LACH, 2000). Sendo assim, a origem do viés relaciona-se tanto a fatores observáveis quanto aos não observáveis e, uma vez sendo possível aplicar à base de dados uma estrutura de painel de efeitos fixos, o método DID possibilita amenizar o viés causado pelos não observáveis. Dessa forma, a remoção das características não observáveis pela estimativa DID viabiliza-se pela especificação em modelos de painel em dois períodos, ao mesmo tempo que permite a inclusão de variáveis de controle que, por sua vez, amenizam o viés advindo dos observáveis.

Com base neste método foram especificadas variáveis (Quadro 1), a fim de gerar o modelo que será apresentado em seguida.

Sendo que cada empresa da amostra foi observada em dois períodos de tempo para cada estimativa referente aos períodos 2003 e 2005, 2005 e 2008 e 2008 e 2011, o modelo assume a seguinte especificação:

$$
\ln P D_{i}=\beta_{0}+\delta_{0} D_{2}+\beta_{1} T_{i}+\beta_{2} X_{i}+\delta_{1} T_{i} D_{2}+\varepsilon_{i}
$$

Onde:

$i=$ empresas e os seguintes parâmetros de estimação:

$\beta_{0}$ : é o valor esperado da variável estudada para o grupo de controle antes da aplicação da Lei. É o intercepto da equação;

$\delta_{0}$ : mede o impacto do segundo período, após a mudança, sobre a variável estudada Representa a tendência temporal comum aos dois grupos; 
$\beta_{1}$ : mede a diferença permanente entre os grupos, que não se explica pela ocorrência do evento exógeno (no caso deste estudo, a aplicação da Lei de Informática);

$\beta_{2}$ : mede o impacto das variáveis de controle de características observáveis das empresas antes da implementação do programa governamental;

$\delta_{1}$ : representa o parâmetro de interesse da regressão. Mede a diferença do grupo de tratamento em relação ao grupo de controle após a ocorrência do evento (aplicação da Lei). É o efeito médio do tratamento, portanto, representa o estimador de diferenças em diferenças. Este coeficiente de interesse (estimador) pode ser expresso da seguinte forma: ${ }^{21}$

$$
\hat{\delta}_{1}=\left(\overline{\mathrm{y}}_{\boldsymbol{p}, \boldsymbol{t}}-\overline{\mathrm{y}}_{\boldsymbol{a}, \boldsymbol{t}}\right)-\left(\overline{\mathrm{y}}_{\boldsymbol{p}, \boldsymbol{c}}-\overline{\mathrm{y}}_{\boldsymbol{a}, \boldsymbol{c}}\right)
$$

Onde: $c=$ controle; $t=$ tratamento; $a=$ antes; e $p=$ pós (depois).

$\mathrm{O}$ estimador de diferenças em diferenças será não-viesado desde que:

- o modelo esteja corretamente especificado, requerendo a inclusão de outras variáveis de controle;

- o termo de erro tenha média igual zero, $E\left[\varepsilon_{i}\right]=0$

- $\operatorname{cov}\left(\varepsilon_{i}, D_{2}\right)=0 ; \operatorname{cov}\left(\varepsilon_{i}, T_{i}\right)=0$ e $\operatorname{cov}\left(\varepsilon_{i}, T_{i} D_{2}\right)=0$

Esta última condição é a hipótese forte do modelo, conhecida como pressuposto da tendência paralela (common trends assumption). A hipótese da tendência paralela significa que o termo de erro não esteja correlacionado com outras variáveis na equação.

Tal hipótese implica admitir que, na ausência do tratamento, tanto o grupo de tratamento quanto o de controle teriam seguido a mesma tendência. Entretanto, não se pode testá-la, uma vez que não é possível observar o grupo de tratamento na ausência de tratamento.

21 Sua derivação resulta de que $\bar{y}_{a, c}$ é o valor médio (da amostra) de $y$ para os indivíduos que estão no grupo de controle antes do tratamento e $\bar{y}_{p, c}$ é o valor médio de $y$ para os indivíduos que estão no grupo de controle depois do tratamento. E $\bar{y}_{a, t}$ é o valor médio (da amostra) de $y$ antes do tratamento e $\overline{\mathrm{y}}_{p, t}$, o valor médio de y depois do tratamento.

A variação média em $y$ para o grupo de controle, portanto, é:

$$
\Delta \overline{\mathrm{y}}_{c}=\overline{\mathrm{y}}_{p, c}-\overline{\mathrm{y}}_{a, c}
$$

A variação média em $y$ para o grupo de tratamento é:

$$
\Delta \overline{\mathrm{y}}_{t}=\overline{\mathrm{y}}_{p, t}-\overline{\mathrm{y}}_{a, t}
$$

A diferença entre essas variaçōes é o estimador de diferenças em diferenças e corresponde à variação média em $y$ para todos os indivíduos que estão no grupo de tratamento menos a variação média em $y$ para todos os indivíduos que estão no grupo de controle. Então, o estimador de diferenças em diferenças pode ser denotado também como:

$$
\hat{\delta}_{1}=\Delta \bar{y}_{t}-\Delta \bar{y}_{c}
$$


Muito embora não exista uma maneira de demonstrar a trajetória paralela dos dois grupos, na ausência da mudança de política, algumas evidências quanto à sua validade podem ser observadas. Sendo assim, é necessário que os dois grupos sigam tendências iguais no tempo. Portanto, $\delta_{0}$, deverá ser comum aos dois, além do período de tempo ser o mesmo e dos fatores não observáveis específicos aos dois serem constantes no tempo.

Conforme exposto acima, foram escolhidas as empresas para as quais estavam disponíveis os dados referentes aos gastos em P\&D anteriores aos respectivos períodos de tratamento. Admite-se que os dados disponíveis para os períodos pré-tratamento de cada estimativa $(2005,2008$ e 2011) para os dois grupos, desde que mostrem igualdade de tendências, são comparáveis (CRESPI et al., 2011). A igualdade de tendências pré-tratamento foi verificada por meio de inspeção visual gráfica, embora tal método sofra limitaçóes dada a impossibilidade de um teste formal para o qual seriam necessários dados de períodos mais longos (ANGRIST; PISCHKE, 2008).

Além disso, é possível que ocorram alterações em características observáveis entre um período e outro, o que poderia comprometer a tendência paralela. No entanto, deve-se ressaltar que, com a inclusão dos regressores adicionais no modelo, cuja omissão poderia estar causando viés nas estimativas, a hipótese da tendência paralela fica fortalecida. ${ }^{22}$

As estatísticas da Tabela 1 descrevem as variáveis utilizadas, possibilitando comparações entre empresas beneficiárias e não beneficiárias da Lei de Informática durante os períodos analisados. As mesmas referem-se à amostra inicial de onde as empresas foram retiradas para a constituição dos grupos de tratamento e de controle.

A variável de resultado está definida em logaritmo natural da intensidade

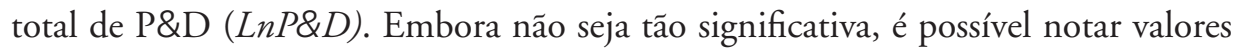
médios mais elevados dos gastos em $\mathrm{P} \& \mathrm{D}$ em relação ao faturamento (intensidade de $\mathrm{P} \& D$ ) para as empresas beneficiárias da Lei. O mesmo é válido para os valores médios das covariadas.

Os valores médios da intensidade de P\&D aumentam até 2008 para as duas modalidades de empresas, sendo que a diferença entre eles, apesar de positiva em favor das beneficiárias, não apresenta crescimento ao longo do período. Tal resultado sugere dúvidas se, de fato, os gastos em P\&D daquelas empresas estariam indo além dos percentuais obrigatórios para se beneficiarem da Lei.

22 Os fatores não observáveis são assumidos como invariáveis no tempo e os fatores observáveis são controlados. 
Tabela 1

Estatísticas descritivas para empresas apoiadas e não apoiadas pela Lei de Informática

Brasil - 2003-2011

\begin{tabular}{|c|c|c|c|c|}
\hline Variáveis & 2003 & 2005 & 2008 & 2011 \\
\hline \multicolumn{5}{|l|}{$\operatorname{LnP\& D}$} \\
\hline \multicolumn{5}{|c|}{ Empresas não apoiadas } \\
\hline Média & 5,38 & 5,58 & 7,16 & 6,25 \\
\hline Desvio padrão & 1,91 & 1,93 & 2,28 & 2,05 \\
\hline Número & 1.600 & 1.792 & 1.235 & 1.317 \\
\hline \multicolumn{5}{|l|}{ Empresas apoiadas } \\
\hline Média & 6,24 & 6,61 & 7,93 & 7,21 \\
\hline Desvio padrão & 2,04 & 1,87 & 2,19 & 2,03 \\
\hline Número & 125 & 150 & 114 & 109 \\
\hline \multicolumn{5}{|c|}{$\operatorname{LnPoPD}$} \\
\hline \multicolumn{5}{|c|}{ Empresas não apoiadas } \\
\hline Média & 1,93 & 1,93 & 2,03 & 2.06 \\
\hline Desvio padrão & 1.22 & 1,22 & 1,21 & 1,30 \\
\hline Número & 1.600 & 1.792 & 1.235 & 1.317 \\
\hline \multicolumn{5}{|l|}{ Empresas apoiadas } \\
\hline Média & 2,32 & 2,48 & 2,66 & 2.74 \\
\hline Desvio padrão & 1,24 & 2,15 & 1,48 & 1,38 \\
\hline Número & 125 & 150 & 114 & 109 \\
\hline \multicolumn{5}{|c|}{ LnVBP } \\
\hline \multicolumn{5}{|c|}{ Empresas não apoiadas } \\
\hline Média & 8,97 & 9,40 & 9,65 & 9.79 \\
\hline Desvio padrão & 245 & 2,21 & 9,65 & 2,03 \\
\hline Número & 1.600 & 1.792 & 1.235 & 1.317 \\
\hline \multicolumn{5}{|l|}{ Empresas apoiadas } \\
\hline Média & 9,65 & 9,93 & 10,13 & 10.46 \\
\hline Desvio padrão & 2,17 & 2.15 & 2,33 & 1,95 \\
\hline Número & 125 & 150 & 114 & 109 \\
\hline \multicolumn{5}{|l|}{ Po } \\
\hline \multicolumn{5}{|c|}{ Empresas não apoiadas } \\
\hline Média & 445,55 & 450,97 & 472 & 454 \\
\hline Desvio padrão & 1289 & 1460 & 1736 & 1789 \\
\hline Número & 1.600 & 1.792 & 1.235 & 1.317 \\
\hline \multicolumn{5}{|l|}{ Empresas apoiadas } \\
\hline Média & 484 & 461 & 635 & 925 \\
\hline Desvio padrão & 1570 & $1,51 \mathrm{e}+07$ & 1711 & 4470 \\
\hline Número & 125 & 150 & 114 & 109 \\
\hline \multicolumn{5}{|c|}{$P o^{2}$} \\
\hline \multicolumn{5}{|c|}{ Empresas não apoiadas } \\
\hline Média & 1.861 .98 & 2.336 .02 & 3.238 .95 & 3.408 .25 \\
\hline Desvio padrão & $2,63 e+07$ & $4,14 \mathrm{e}+07$ & $6,52 \mathrm{e}+07$ & $6,61 e+07$ \\
\hline Número & 1.600 & 1.792 & 1.235 & 1.317 \\
\hline \multicolumn{5}{|l|}{ Empresas apoiadas } \\
\hline Média & 2.683 .67 & 2.030 .73 & 3.317 .32 & $2.07 e+07$ \\
\hline Desvio padrão & $1,68 e+07$ & $1,51 \mathrm{e}+07$ & $1,87 e+07$ & $2,39 \mathrm{e}+08$ \\
\hline Número & 125 & 150 & 114 & 109 \\
\hline
\end{tabular}

Fonte: Microdados da Pintec-IBGE. Elaboração própria. 
Conforme ressaltado anteriormente, a partir de 2004 modificou-se a base de cálculo sobre a qual se aplicam os percentuais de benefícios tributários. Até então aplicavam-se 5\% sobre o faturamento total da empresa. Posteriormente, a dedução passou a ser feita apenas sobre o faturamento dos produtos incentivados pela Lei.

A análise de Salles Filho et al. (2012), por exemplo, constatou que, entre 2003 e 2008, o investimento em P\&D, para o grupo de empresas beneficiárias analisadas, cresceu 30\% (de R \$ 670 milhões/ano para R \$ 879 milhôes/ano), sendo que houve aumento, em média, de $40 \%$ em relação à obrigação legal. ${ }^{23}$ Apesar de expressivo, o volume foi inferior ao período que abrange fins dos anos 1990 e início dos 2000, quando, em média, ficou em 1 bilhão de reais. Segundo os autores, as mudanças ocorridas após 2004 tiveram importância na explicação dessa redução.

Além disso, conforme evidências do estudo citado, o investimento que se verifica no período até 2008 , como decorrência da mudança na base de cálculo, direcionou-se fortemente ao desenvolvimento de produtos, e não à pesquisa. ${ }^{24}$

A Tabela 1 demonstra que, em geral, os valores médios mais elevados situam-se em 2008. Já em 2011 os indicadores abaixo mostram que tais valores foram reduzidos em relação ao período anterior. Um importante dado observado em 2008 e 2011 é quanto ao valor médio da variável $P o$, proxy do tamanho da empresa. Nota-se que a diferença de valores entre as apoiadas e não apoiadas torna-se bem mais expressiva, evidenciando, para as primeiras, maior frequência de empresas maiores. Assim, a maior participação das mesmas coincide com os valores médios mais elevados da intensidade de P\&D.

\section{Resultados}

Conforme se observa na Tabela 2, os sinais exibidos pelos parâmetros da variável de interesse (TiD2) são positivos, porém houve significância somente para a estimativa de 2005-2008, evidenciando que, neste caso único, houve adicionalidade. À exceção do volume de mão de obra ( $P o$ ) nas estimativas de 2003-2005 e 20052008, os demais parâmetros das variáveis de controle mostraram significância e são consistentes com o comportamento evidenciado pela literatura, em que uma maior participação relativa da mão de obra especializada em $\mathrm{P} \& \mathrm{D}$ em período integral, assim como o valor bruto da produção, influencia a intensidade de P\&D.

23 Conforme base de dados da Secretaria para a Política de Informática do Ministério da Ciência e Tecnologia (Sepin/MCT) (SALLES FILHO et al., 2012, p. 7).

24 Um exemplo é o desenvolvimento de software embarcado em equipamentos que correspondeu, segundo os autores do estudo, a $60 \%$ das atividades de P\&D do período. 
Tabela 2

Estimativas em diferenças de diferenças para os impactos da Lei de Informática em empresas de alta tecnologia pertencentes ao complexo eletrônico

Brasil - 2003-2011

\begin{tabular}{|c|c|c|c|}
\hline Variáveis & 2003-2005 & 2005-2008 & 2008-2011 \\
\hline lpopd & $\begin{array}{r}0,585^{* * *} \\
(0,131)\end{array}$ & $\begin{array}{r}0,482^{\text {*** }} \\
(0,130)\end{array}$ & $\begin{array}{r}0,459^{* * *} \\
(0,112)\end{array}$ \\
\hline lvbp & $\begin{array}{r}0,458^{* * *} \\
(0,111)\end{array}$ & $\begin{array}{c}0,219^{* *} \\
(0,0934)\end{array}$ & $\begin{array}{c}0,329^{* * *} \\
(0,0956)\end{array}$ \\
\hline po & $\begin{array}{r}0,000215 \\
(0,000767)\end{array}$ & $\begin{array}{r}0,00169 \\
(0,00116)\end{array}$ & $\begin{array}{c}0,000598^{* *} \\
(0,000249)\end{array}$ \\
\hline po2 & $\begin{array}{r}-5,72 \mathrm{e}-09 \\
(2,58 \mathrm{e}-07)\end{array}$ & $\begin{array}{r}-4,38 e-07 \\
(4,58 e-07)\end{array}$ & $\begin{array}{r}-3,44 \mathrm{e}-08^{* *} \\
(1,38 \mathrm{e}-08)\end{array}$ \\
\hline a2005 & $\begin{array}{c}0,393^{* *} \\
(0,189)\end{array}$ & & \\
\hline a2008 & & $\begin{array}{r}0,154 \\
(0,781)\end{array}$ & \\
\hline a2011 & & & $\begin{array}{r}0,363 \\
(0,161)\end{array}$ \\
\hline TiD2 & $\begin{array}{r}0,570 \\
(0,516)\end{array}$ & & \\
\hline TiD2 & & $\begin{array}{c}0,549^{* *} \\
(0,212)\end{array}$ & \\
\hline TiD2 & & & $\begin{array}{r}0,118 \\
(0,237)\end{array}$ \\
\hline Ti & $\begin{array}{r}-0,0672 \\
(0,652)\end{array}$ & & \\
\hline Ti & & $\begin{array}{l}-0,424 \\
(0,819)\end{array}$ & \\
\hline Ti & & & $\begin{array}{r}0,117 \\
(0,621)\end{array}$ \\
\hline Constante & $\begin{array}{r}-0,0602 \\
(0,820)\end{array}$ & $\begin{array}{r}2,442^{* * *} \\
(0,729)\end{array}$ & $\begin{array}{r}2,348^{* * *} \\
(0,765)\end{array}$ \\
\hline Observaçōes & 165 & 107 & 104 \\
\hline $\mathrm{R}^{2}$ & 0,707 & 0,536 & 0,602 \\
\hline
\end{tabular}

Fonte: IBGE/CDDI-GEATE - Elaboração própria a partir dos microdados da Pintec ediçôes: 2003, 2005, 2008 e 2011.

Nota: Erros-padrão robustos reportados em parênteses abaixo dos respectivos parâmetros.

Níveis de significância: ${ }^{*}, * *, * *, 10 \%, 5 \%$ e $1 \%$, respectivamente. 
Embora não haja evidências de efeitos-substituição (crowding out) pela Lei de Informática, a ausência de significância dos parâmetros em todas as estimativas não permite afirmar que a mesma tem sido eficaz em produzir aumentos dos gastos em P\&D por parte das empresas beneficiárias no setor. Isso sugere dúvidas se realmente há persistência quanto à eficácia da Lei, já que os efeitos diferem ao longo do tempo, não sendo significativos e positivos para todos os períodos.

Tendo em vista o comportamento de algumas variáveis a partir da análise descritiva, apresentada no item anterior, torna-se relevante mencionar o ambiente conjuntural dos períodos, sobretudo em 2008 e 2011, pois as oscilações de mercado afetam as decisōes de inovar das empresas e, assim, os investimentos em P\&D.

O cenário adverso que se formou na esteira da crise de 2008 pode ter influenciado as decisões das empresas que, em face da maior incerteza, alteraram seu comportamento quanto aos investimentos de maior risco. Naquele contexto, apesar da recuperação econômica em 2010, o ano de 2011 registrou forte queda de 8,7\% do valor adicionado da indústria de transformação em relação a $2008 .{ }^{25}$

Embora não seja possível saber exatamente qual teria sido a queda do faturamento com produtos incentivados pela Lei, o cenário gerado pela crise sugere ter ocorrido menor direcionamento dos montantes relativos às vendas destinados à $\mathrm{P} \& \mathrm{D}$ por parte das empresas beneficiárias. Nesse sentido, para a amostra de empresas analisadas, observou-se pelos dados da Tabela 1 que, entre 2008 e 2011, houve ligeira queda nos montantes destinados aos gastos em P\&D em relação às vendas.

As características conjunturais mais favoráveis até 2008 coincidem, conforme já exibido pelos dados, com a participação mais relevante de empresas beneficiárias de maior porte a partir daquele ano. Considerando tais fatos e associando-os aos montantes médios mais elevados de gastos em P\&D em relação às vendas em 2008, é possível que aí estejam alguns elementos que ajudem a explicar o único momento em que houve adicionalidade como efeito da Lei de Informática.

Em linhas gerais, a metodologia proposta mensura se a variação de gastos de um período para outro, e em cada estimativa, pode ser explicada pela Lei de Informática. A validade desse tipo de abordagem, enquanto contributiva ao conjunto dos trabalhos empíricos, é sua capacidade em tratar o problema do viés de seleção, já que este tem sido um dos principais problemas nas avaliaçôes dos impactos de políticas de inovação. Ao empregar o método DID com covariadas, torna-se possível controlar a influência dos fatores observáveis e, ao mesmo tempo, amenizar vieses causados pelos não observáveis.

25 Pesquisa de Inovação 2011 (IBGE, 2013) 
No entanto, as estimativas sofreram limitações, uma vez que não foi possível incorporar mais variáveis de controle no modelo, já que nem sempre as mesmas estavam disponíveis para todas as empresas das bases de dados utilizadas. Esta foi uma limitação que contribuiu para reduzir o tamanho das amostras.

É necessário ainda destacar a difículdade em concluir os resultados comparando-os a outros estudos que procuraram estimar os efeitos da Lei sobre empresas inovadoras. Isto não somente porque há diferenças quanto aos métodos empregados, além de período de análise, mas também porque, diferentemente dos outros, à exceção de Kannebley Jr. e Porto (2012), a proposta aqui foi verificar o impacto sobre a intensidade de $P \& D$ enquanto variável dependente. ${ }^{26}$

Outro ponto é que outros estudos definem um conjunto mais amplo de gastos em atividades inovativas (AVELLAR; BOTELHO, 2016), ou procuram captar o impacto da Lei sobre outra variável de interesse, como Ribeiro et al. (2011), que avaliaram os efeitos sobre a produtividade. Apesar da relevancia destes outros aspectos e da influencia exercida pelo instrumento, a Lei, ao condicionar os incentivos fiscais aos aumentos de gastos em P\&D, sugere que os resultados positivos sejam mais prováveis. Po esta razão justifica-se o interesse do artigo, optando por captar os efeitos somente sobre este tipo específico de gasto inovativo.

Ainda em relação às comparações entre estudos há outra dificuldade. Em decorrência de a Lei de Informática possuir características tanto de incentivos fiscais como de subsídios propriamente ditos, conforme visto anteriormente, fica limitada a comparação com estudos empíricos internacionais, já que se trata de um instrumento de apoio específico ao país.

\section{Conclusões}

A Lei de Informática é um instrumento de política industrial voltada para o estímulo dos setores que integram o complexo eletrônico do país. Enquanto um incentivo fiscal, tal instrumento visa estimular gastos em P\&D e, ao mesmo tempo, fortalecer sua cadeia produtiva por meio da internalização de etapas com maior agregação de valor interno. A sua efetividade contribuiria para melhorar a competitividade industrial ao elevar as competências tecnológicas empresariais e permitir o adensamento produtivo e tecnológico dos setores beneficiados. Diante dessa importância e visando uma adequação do desenho e implantação da mesma, impõe-se a necessidade de avaliar sua efetividade, mensurando os resultados em empresas beneficiárias.

26 Um detalhe é que o presente artigo calculou a P\&D total, considerando a somatória tanto da P\&D interna quanto externa 
O método aplicado no presente artigo possibilitou mensurar se os gastos em P\&D das empresas beneficiárias elevaram-se de forma significativa quando comparadas às não beneficiárias. Esta análise foi feita comparando a variação de gastos entre ambas ocorrida entre o período em que houve o acesso à Lei para as primeiras e o período anterior, em que nenhuma teve acesso. Foram construídos três painéis subsequentes em que os efeitos, apesar de positivos, foram significativos em apenas um momento. Tal resultado não permite afirmar que a Lei tem sido eficaz de forma persistente ao longo do tempo.

Da mesma forma, não foram encontrados efeitos de substituição (crowding out) que revelariam haver simples troca entre recursos privados e recursos públicos para projetos de $P \& D$ que, de uma forma ou outra, seriam executados.

Ou seja, embora a Lei não leve as empresas pertencentes ao complexo eletrônico a aumentar seus recursos próprios nas atividades de $\mathrm{P} \& \mathrm{D}$, é possível que ela tenha contribuído para que algumas delas aumentassem seus gastos. Porém, tal conclusão não se generaliza ao setor como um todo.

Um dos problemas apontado pela literatura é a baixa eficácia da Lei em internalizar etapas de produção de valor agregado mais elevado. Tal fato, reconhecido pela perda de participação de alguns setores de alta tecnologia na indústria de transformação, e mensurado pela queda do valor da transformação industrial, sugere ser uma das causas para que os níveis de gastos em P\&D sejam limitados, pois a menor complexidade exigida na produção interna talvez implique projetos cujos gastos não requerem montantes tão elevados.

Deve ser lembrado que os projetos de P\&D de maior complexidade envolvem riscos elevados associados, em maior magnitude, às fases de pesquisa quando comparados às fases de desenvolvimento. Tal aspecto é relevante quando se discute a questão das políticas de apoio à P\&D, porque a maior complexidade tecnológica, que supostamente envolveria maior alcance em mercados dinâmicos, melhorando a competitividade industrial, acaba por não atrair de forma suficiente os investimentos privados, embora apresentem taxas de retorno elevadas, conforme argumentado por Tassey (2005).

É nesse ponto que os instrumentos de política seriam importantes para reduzir os riscos e permitir que a relação entre as taxas de retorno e risco fossem aceitáveis naquelas fases mais distantes da comercialização.

Além disso, o foco das empresas do setor é o mercado interno, com predomíno de estratégias de adaptação e melhorias de produtos. Isso reforça o argumento já mencionado de que os investimentos são, em sua maioria, voltados para o de- 
senvolvimento de produtos, e não para a pesquisa. Tal fato sugere que a atuação da Lei tem pouco impacto sobre aquelas fases em que a redução de riscos atrairia investimentos de retornos mais elevados, estimulando as empresas a executar projetos mais arrojados. Nesses casos, seria esperado que os estímulos gerados pelo instrumento, ao atuar sobre riscos e custos, levassem ao maior aporte de recursos próprios, caracterizando efeitos de adicionalidade.

Sendo assim, há dúvidas se alterações da Lei que permitam uma abrangência de empresas, como foi o caso após 2004, resultem em aumentos persistentes e contínuos dos gastos privados em P\&D. Embora tais alterações sejam positivas quanto ao aumento da participação de empresas e, por exigência, obriguem as mesmas a elevar aqueles gastos, não se altera a natureza da P\&D, voltada para fases de desenvolvimento.

Ao mesmo tempo, a falta de evidências de resultados positivos e significativos em todas as estimativas leva a crer que a Lei também não tem sido suficiente para estancar a perda de participação desses setores na estrutura industrial do país, significando a existência de baixa correlação entre o montante de P\&D realizado e o peso relativo daqueles setores. Isso não resulta em ganhos de participação no valor da transformação industrial e, portanto, não atinge os resultados esperados em termos de ganhos de competitividade.

Este último aspecto talvez seja um ponto a ser explorado em pesquisas futuras por meio de estimativas baseadas em outros métodos que possam captar em que medida os gastos em P\&D de todo o complexo eletrônico são influenciados pelo valor da transformação industrial de cada setor aí pertencente, e em que medida seriam resultantes de suas respectivas intensidades de $\mathrm{P} \& \mathrm{D}$ que, por natureza, são mais elevadas em relação aos outros setores da indústria.

Por fim, como sugestão de estudos futuros que possam superar uma limitação do presente artigo, recomenda-se que outros modelos sejam testados, incorporando, inclusive, dados mais recentes da Pintec.

\section{Referências bibliográficas}

ANGRIST, J. D.; PISCHKE, J.-S. Mostly harmless econometrics: an empiricist's companion. Princeton, NJ: Princeton University Press, 2008.,

ARROW, K. Economic welfare and the allocation of resources for invention. In: UNIVERSITIES-NATIONAL BUREAU COMMITTEE FOR ECONOMIC RESEARC. 
The rate and direction of inventive activity: economic and social factors. Princeton, NJ: Princeton University Press, 1962. v. I, p. 609-626. Disponível em: <from http://www.nber. org/books/univ62-1>.

ASCHHOFF, B. The effect of subsidies on R\&D investment and success: do subsidy history and size matter? ZEW - Zentrum für Europäische Wirtschaftsforschung / Center for European Economic Research, 2009 (ZEW Discussion Papers, n. 09-032). Disponível em: <https:// ideas.repec.org/p/zbw/zewdip/09032.html>.

AVELlAR, A. P.; BOTELHO, M. R. Efeitos das políticas de inovação nos gastos com atividades inovativas das pequenas empresas brasileiras. Revista Estudos Econômicos, v. 46, n. 3, p. 609-642, jul./set. 2016.

BLOOM, N.; GRIFFITH, R.; VAN REENEN, J. Do R\&D tax credits work ? Evidence from a panel of countries 1979 - 1997. London: Centre for Economic Policy Research, 2002 (CEPR Discussion Papers, n. 2415).

BODAS FREITAS, I. et al. Sectors and the additionality effects of R\&D tax credits: a crosscountry microeconometric analysis. Research Policy, v. 46, n. 1, p. 57-72, 2017.

BUISSERET, T. J.;\& CAMERON, H. M. What difference does it make? Additionality in the public support of R\&D in large firms. International Journal of Technology Management, v. 10, n. 4/5/6, p. 587-600, 1995.

BUSOM, I. An empirical evaluation of the effects of $R \& D$ subsidies. Berkeley, CA: University of California, 1999 (Burch Working Paper, n.

B99-05). Disponível em: <http://eml.berkeley.edu// - burch/rdsub.pdf>.

CERULLI, G.; POTİ, B. Evaluating the robustness of the effect of public subsidies on firms' R\&D: an application to Italy. Journal of Applied Economics, v. 15, n. 2,p. 287-320, 2012.

CRESPI, G. et al. Evaluating the impact of science, technology and innovation programs: a methodological Toolkit. IDB - Inter-American Development BanK, 2011 (Impact-Evaluation Guidelines, Tchnical Notes, n. 333). Disponível em: <https://publications.iadb.org/bitstream/ handle/11319/5396/>.

CZARNITZKI, D.; ALMUS, M. The effects of public R\&D subsidies on firms' innovation activities: the case of Eastern Germany. ZEW - Zentrum für Europäische Wirtschaftsforschung / Center for European Economic Research, 2010 (ZEW Discussion Papers, n. 01-10).

CZARNITZKI, D.; HUSSINGER, K. The link between $R \& D$ Subsidies, $R \& D$ spending and technological performance. ZEW - Zentrum für Europäische Wirtschaftsforschung / Center for European Economic Research, 2004 (ZEW Discussion Papers, n. 56-04. 
CZARNITZKI, D.; LICHTENBERG, G. Additionality of Public R\&D grants in a transition economy: the case of eastern Germany. Leuven: Katholische Universiteit Leuven, Department of Applied Economics KU, 2005 (Dept. of Applied Economics Paper, n. OR 0528),

David, P. A.; Hall, B. H. Heart of darkness: modeling public-private funding interactions inside the R\&D black box. Research Policy, v. 29, n. 9, p. 1165-1183, 2000.

David, P. et al. Is public R\&D a complement or substitute for private R\&D? A review of the econometric evidence. Research Policy, v. 29, n. 4/5, p. 497-529, 2000.

GARCÍA-QUEVEDO, E. et al. Assignation of public subsidies: do the experts choose the most efficient $R \& D$ projects? Barcelona: Institut d' Ecomomia de Barcelona, 2008 (Document de Traball, 2008-5).

GARCIA, R.; ROSELINO, J. E. Uma avaliação da Lei de Informática e de resultados como instrumento indutor de desenvolvimento tecnológico e industrial. Gestão \& Produção, v. 11, n. 2, p. 177-185, 2004.

HALL, B. H.; VAN REENEN, J. How effective are fiscal incentives for R\&D? A review of the evidence. Cambridge, MA: National Bureau of Economic Research, 1999 (Working Paper, n. 7098).Disponível em: <http://www.nber.org/papers/w7098>.

HECKMAN, J. J. et al. Characterizing selection bias using experimental data. Cambridge, MA: National Bureau of Economic Research, 1998 (NBER Working Paper, n. 6699). Disponível em: <http://www.nber.org/papers/w6699>.

HOWE, J. D.; MCFETRIDGE, D. G. The Determinants of R \& D Expenditures. The Canadian Journal of Economics, v. 9, n. 1, p. 57-71, 1976.

KANNEBLEY JR., S.; PORTO, G. Incentivos fiscais à Pesquisa, Desenvolvimento e Inovação no Brasil: uma avaliação das políticas recentes. Banco Interamericano de Desenvolvimento (BID), Divisão de Competitividade e Inovação, 2012 (Documento para discussão, n. 236).

KLETTE, T. J. et al. Do subsidies to commercial R\&D reduce market failures? Microeconometric evaluation studies. Research Policy, v. 29, n. 4/5, p. 471-495, 2000.

LACH, S. Do R\&D subsidies stimulate or displace private R\&D ? Evidence from Israel. Cambridge, MA: National Bureau of Economic Research, 2000 (NBER Working Paper, n. 7943).

LECHNER, M. The estimation of causal effects by difference-in-difference methods. Foundations and Trends in Econometrics, v. 4, n. 3, p. 165-224, 2011.

LEYDEN, P.; LINK, A. N. The effects of governmental financing on firms' R\&D activities: an theoretical and emprical investigation. Technovation, v. 9, n. 7, p. 561-575, November 1990. 
MARIA, R.; GUTIERREZ, V. Complexo eletrônico : Lei de Informática e competitividade. Rio de Janeiro: BNDES Setorial, 2010..

MARINO, M. et al. Additionality or crowding-out? An overall evaluation of public R\&D subsidy on private R\&D expenditure. Research Policy, v. 45, n. 9, p. 1715-1730, 2016.

MONTMARTIN, B.; HERRERA, M. Internal and external effects of $R \& D$ subsidies and fiscal incentives: empirical evidence using spatial. GREDEG - Groupe de Recherche en Droit, Economie, Gestion, 2014 (GREDEG Working Papers Series, n. 2014-09). Disponível em: <http://www.gredeg.cnrs.fr/working-papers.html>.

NELSON, R. The simple economics of basic scientific research. Journal of Political Economy,v. 67, n. 3, p. 297-306, jun. 1959.

PACHECO, C. A. O financiamento do gasto em P\&D do setor privado no Brasil e o perfil dos incentivos. Revista USP, n. 89, p. 256-276. mar./maio 2011.

PAVITT, K. Sectoral patterns of technical change: towards a taxonomy and a theory. Research Policy, v. 13, n. 6, p. 343-373, 1984.

PROCHNIK, V. et al. A política da política industrial : o caso da Lei de Informática. Revista Brasileira de Inovação, v. 14, p. 133-152, 2015.

RIBEIRO, E. et al. Productivity in the Brazilian informatics industry and public. In: $39^{\circ}$ ENCONTRO NACIO- NAL DE ECONOMIA. Anais... Foz do Iguaçu-PR: Anpec, 2011.

SALLES FILHO et al. Avaliação de impactos da Lei de Informática: uma análise da política industrial e de incentivo à inovação no setor de TICs brasileiro. Revista Brasileira de Inovação, v. 11, n. esp., p. 191-218, 2012.

TASSEY, G. The disaggregated technology production function: a new model of university and corporate research. Research Policy, v. 34, n. 3, p. 287-303, 2005.

WALLSTEN, S. The effects of government-industry R\&D programs on private R\&D: the case of the Small Business Innovation Research program. RAND Journal of Economics, v. 31, n. 1, p. 82-100, 2000.

WOOLDRIDGE, J. Introdução à Econometria: uma abordagem moderna. São Paulo: Cengage Learning, 2011. 